\title{
Sustained release oral aminophylline in patients with airflow obstruction
}

\author{
A P GREening, E BAILlie, H R GRIBBIN, AND N B PRIDE \\ From the Department of Medicine, Hammersmith Hospital, London
}

\begin{abstract}
Twenty-four patients with reversible airflow obstruction under suboptimal control on conventional therapy entered a double-blind placebo-controlled trial of additional oral sustained release aminophylline. Assessment was by diary cards, twice daily PEFR, and weekly $\mathrm{FEV}_{1}$. Nineteen patients completed the trial satisfactorily. Eleven were improved subjectively by addition of aminophylline. The mean PEFR for all 19 patients rose from $2321 \mathrm{~min}^{-1} \mathrm{SEM} \pm 5$, to $2471 \mathrm{~min}^{-1} \mathrm{SEM} \pm 4(\mathrm{p}<0.0001)$; nine individuals showed a statistically significant improvement in mean PEFR and 10 showed an improvement of $>200 \mathrm{ml}$ in their $\mathrm{FEV}_{1}$. Improvement in PEFR on aminophylline was not at the expense of benefit from inhaled salbutamol. Unwanted effects of nausea, headache, and abdominal discomfort were recorded by 12 of the 24 patients entering the trial. Seventeen of the 19 patients completing the trial had plasma theophylline levels in the accepted therapeutic range of $10-20 \mathrm{mg} \mathrm{l}^{-1}$. The drug doses required to achieve these levels varied from $8 \cdot 6-30.8 \mathrm{mg} \mathrm{kg}^{-1} 24 \mathrm{hr}^{-1}$ in the patients with no clinical or biochemical evidence of liver disease. Oral aminophylline can improve control of airflow obstruction in patients with moderately severe disease who are already receiving multiple medication, but sideeffects often limit its use. The wide dose range required to achieve therapeutic plasma levels indicates that measurements of plasma theophylline are necessary for adequate interpretation of trials of theophylline compounds.
\end{abstract}

Intravenous theophylline preparations have been used in the management of asthma since 1937. Latterly, the increased availability of plasma theophylline measurements has led to a re-evaluation of intravenous dose schedules. ${ }^{12}$ It is generally agreed that peak plasma theophylline levels should be kept below $20 \mathrm{mg}^{-1}$ while trough levels should remain above $10 \mathrm{mg} \mathrm{l}^{-1}$. Similar principles apply to oral preparations. ${ }^{34}$ The recent development of a sustained release oral aminophylline preparation in a lipid base (Phyllocontin Continus Tablets, Napp Laboratories) has enabled the maintenance of such plasma theophylline levels when the drug is given 12-hourly. ${ }^{5}$ We have examined whether this drug can improve the control of airflow obstruction in patients in whom existing treatment was providing suboptimal control.

Address for reprint requests: Dr AP Greening, Department of Medicine Hammersmith Hospital, Du Cane Road, London W12 0HS.

\section{Methods}

Twenty-four patients, 13 men and 11 women, of mean age 57 years (range 19 to 71 years), with reversible airflow obstruction who attended Hammersmith Hospital regularly were entered into the trial (table 1). Approval of the local ethics committee and informed consent from the patients were obtained. All patients had moderately severe airflow obstruction requiring multiple medication. Twenty were regularly using inhaled steroids and six of these required regular oral steroid therapy in addition. Twenty-three were receiving inhaled, and two oral, $\beta$-agonists; one used disodium cromoglycate and one ipratropium bromide. Individual dose requirements of aminophylline were determined during an open phase preceding the trial. Plasma theophylline was measured by high pressure liquid chromatography ${ }^{6}$ at times of peak (four to six hours post dosage) or trough (10 to 12 hours post dosage) plasma levels and were re- 
Table 1 Age, sex, dose of Phyllocontin, plasma theophylline levels, and side-effects in 24 patients entered into the trial

\begin{tabular}{|c|c|c|c|c|c|c|}
\hline $\begin{array}{l}\text { Trial } \\
\text { number }\end{array}$ & $\begin{array}{l}\text { Age } \\
(y r)\end{array}$ & Sex & $\begin{array}{l}\text { Dose } \\
(m g / 24 h r)\end{array}$ & $\begin{array}{l}\text { Dose } \\
(m g / k g / \\
24 h r)\end{array}$ & $\begin{array}{l}\text { Plasma } \\
\text { theophyl- } \\
\text { line* }^{*}\end{array}$ & $\begin{array}{l}\text { Side- } \\
\text { effects† }\end{array}$ \\
\hline 1 & 61 & $\mathbf{M}$ & 1350 & $19 \cdot 2$ & ++ & 0 \\
\hline 2 & 66 & $\mathbf{M}$ & 2250 & 30.8 & + & 0 \\
\hline 3 & 70 & $F$ & 900 & $14 \cdot 4$ & \pm & + \\
\hline 4 & 59 & $\mathbf{F}$ & 900 & $12 \cdot 6$ & $\bar{t}+$ & +++ \\
\hline $5 \|$ & 68 & $\mathbf{F}$ & 650 & $11 \cdot 8$ & + & $+t+$ \\
\hline 6 & 26 & $\mathbf{M}$ & 850 & $11 \cdot 4$ & ++ & +++ \\
\hline 7 & 71 & $\mathbf{F}$ & 900 & $16 \cdot 2$ & + & ++ \\
\hline 8 & 19 & $\mathbf{F}$ & 900 & $18 \cdot 6$ & + & 0 \\
\hline 9 & 60 & $\mathbf{M}$ & 1100 & $14 \cdot 2$ & ++ & 0 \\
\hline 10 & 55 & $\mathbf{M}$ & 900 & $12 \cdot 2$ & \pm & 0 \\
\hline $11_{+}^{+}$ & 63 & $\mathbf{M}$ & 500 & $7 \cdot 0$ & + & $++t$ \\
\hline 12 & 59 & $\mathbf{M}$ & 900 & $12 \cdot 8$ & ++ & 0 \\
\hline 13 & 68 & $\mathbf{F}$ & 650 & $12 \cdot 0$ & + & ++ \\
\hline 14 & 59 & $\mathbf{M}$ & 1350 & $14 \cdot 8$ & + & 0 \\
\hline 15 & 68 & $\mathbf{F}$ & 900 & $20 \cdot 0$ & ++ & + \\
\hline 16 & 65 & $\mathbf{F}$ & 650 & $10 \cdot 8$ & + & $+t$ \\
\hline $17 \|$ & 58 & $\mathbf{M}$ & 800 & $10 \cdot 2$ & \pm & +++ \\
\hline $18 \|$ & 68 & F & 650 & $9 \cdot 7$ & $\overline{? \S}$ & $++t$ \\
\hline $19^{\prime \prime}$ & 25 & $\mathbf{F}$ & 650 & $12 \cdot 6$ & + & 0 \\
\hline 20 & 53 & $\mathbf{M}$ & 1350 & $19 \cdot 2$ & $+t$ & 0 \\
\hline 21 & 68 & $\mathbf{M}$ & 650 & $8 \cdot 6$ & + & 0 \\
\hline 22 & 62 & $\mathbf{M}$ & 1100 & $12 \cdot 8$ & + & 0 \\
\hline 23 & 50 & $\mathbf{M}$ & 1350 & $15 \cdot 8$ & $+t$ & 0 \\
\hline $24 !$ & 41 & F & 900 & $13 \cdot 6$ & ++ & ++ \\
\hline
\end{tabular}

$*++=$ peak level $>15 \mathrm{mg} \mathrm{l}^{-1}$ and/or trough level $>10 \mathrm{mg} \mathrm{l}^{-1} ;+=$ peak level $10-15 \mathrm{mg}^{-1}$ and/or trough level $<10 \mathrm{mg} \mathrm{l}^{-1}$; \pm peak level $<10 \mathrm{mg} \mathrm{1}^{-1}$.

$\dagger 0=$ none; $+=$ present on at least seven of the 28 days but only transient (one to two hours) in nature; $++=$ present on most days but of limited duration; $+++=$ virtually constant.

$\ddagger$ Patient has alcohol-induced cirrhosis of the liver.

$\S$ Patient discontinued the drug before a plasma theophylline estimation could be made.

II = unable to complete the trial satisfactorily.

peated if unsatisfactory after a minimum interval of three days. Using these levels the daily doses were adjusted so that, as near as possible, plasma theophylline levels remained in the range 10 to $20 \mathrm{mg} \mathrm{l}^{-1}$ throughout the 12-hour interdosage period.

A double-blind crossover trial design was used with patients receiving four consecutive weeks of active and four consecutive weeks of placebo medication in a randomly allocated order. The tablets were taken 12-hourly. Throughout the period of the trial all patients continued their other medications in unaltered dosage. Eight patients used an inhaled $\beta$-agonist regularly four times daily. The others recorded the frequency of their inhaler use. During the trial patients kept a diary of their respiratory symptoms ("better, worse, or no change from usual") and of possible unwanted effects from the medication. They also measured, before any use of $\beta$-agonists, their peak expiratory flow rate (PEFR) first thing in the morning and last thing at night and recorded the best value obtained in three attempts. The eight patients using inhaled $\beta$-agonists regularly re- $\stackrel{\overrightarrow{\bar{O}}}{\stackrel{\overrightarrow{0}}{+}}$ peated their PEFR 15 minutes after using the inhaler. Statistical analysis of the PEFR records $\underline{\bar{\sigma}}$ was by Student's paired $t$ test. All patients were $\frac{\bar{\sigma}}{\bar{\phi}}$ seen weekly when their forced expiratory volume $\stackrel{\varnothing}{\AA}$ in one second $\left(\mathrm{FEV}_{1}\right)$ and slow vital capacity (VC) were measured on a dry spirometer. The best $\vec{O}$ value of three estimates was recorded. Weekly blood samples were taken for analysis of plasma $\vec{\omega}$ theophylline levels. This was performed by one $\stackrel{\Omega}{\rightleftharpoons}$ of us (EB) on coded specimens, the trial code to $\vec{x}$ be broken for ethical reasons if any plasma sample $\omega_{\sigma}$ had a theophylline level of $>25 \mathrm{mg}^{-1}$. The results of the plasma theophylline levels were $\omega_{0}$ withheld from the clinical assessor until after the $\omega$ end of the trial.

\section{Results}

The results from 19 patients were suitable for full $\vec{\oplus}$ analysis. Of the remaining five patients three $\stackrel{\infty}{\rightarrow}$ $(5,17$, and 18) withdrew because of side-effects and two were withdrawn because of irregular attendance (24) and irregular compliance with medication (7).

\section{PLASMA THEOPHYLLINE LEVELS}

Peak levels were between 15 and $20 \mathrm{mg} \mathrm{l}^{-1}$ in nine patients, between 10 and $15 \mathrm{mg} \mathrm{l}^{-1}$ in eight patients, and below the desired minimum of $10 \mathrm{mg}^{-1}$ in two patients (table 1). The daily maintenance dose used to achieve these levels varied between $7 \cdot 0$ and $30.8 \mathrm{mg} \mathrm{kg}^{-1}$, which represented doses from 450 to $2250 \mathrm{mg}$ per 24 hours.

\section{SUBJECTIVE AND OBJECTIVE BENEFITS}

Eleven of the 19 patients recorded subjective benefit while on the active drug and none while on the placebo (table 2). The mean PEFR was slightly $\mathrm{O}$ higher on the active drug $\left(2471 \mathrm{~min}^{-1}, \mathrm{SEM} \pm 4\right)$ than on placebo $\left(2321 \mathrm{~min}^{-1}, \mathrm{SEM} \pm 5\right),(\mathrm{p}<0.001)$ (figure). In nine patients PEFR on the active drug $N$ was significantly greater than on placebo, in nine there was no significant difference, and in one $\widetilde{N}$ there was a small but statistically significant reduction in PEFR while on the active preparation (table 2). The mean weekly $\mathrm{FEV}_{1}$ during treat- 0 ment was $201 \mathrm{ml}$ larger than on placebo $(\mathrm{p}<0 \cdot 001)$. Seventeen of the 19 patients showed some improvement in $F E V_{1}$, the remaining two showing no change (figure, table 2). All of the eight patients using inhaled $\beta$-agonists regularly were responsive to this treatment (mean rise in PEFR during control period of $\left.471 \mathrm{~min}^{-1}\right)$, but only four $(2,15,21$, and 23) showed a significant improvement in 8 pre-bronchodilator PEFR on aminophylline. These





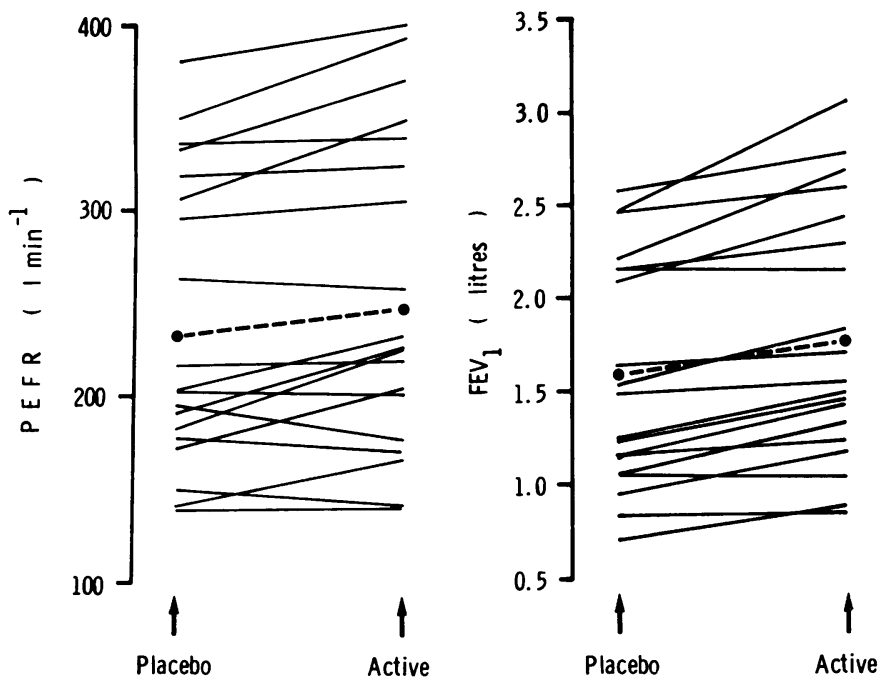

Figure Comparisons of the mean daily PEFR and mean weekly FEV for 19 patients during periods of treatment with placebo and with sustained release aminophylline tablets. Group means are indicated by the solid circles joined by dashed lines.

Table 2 Patient number, mean weekly FEV , and daily PEFR during periods when placebo and active drugs were added to the standard medication in the 19 patients who successfully completed the trial

\begin{tabular}{|c|c|c|c|c|c|c|c|c|c|c|c|}
\hline \multirow{3}{*}{$\begin{array}{l}\text { Patient } \\
\text { rumber }\end{array}$} & \multicolumn{2}{|l|}{$F E V_{1}(l)$} & \multicolumn{2}{|c|}{$F E V_{1}(\% \text { best })^{*}$} & \multirow{2}{*}{\multicolumn{3}{|c|}{$\frac{\text { Before bronchodilator }}{\operatorname{PEFR}\left(\operatorname{lmin}^{-1}\right) \dagger}$}} & \multirow{2}{*}{\multicolumn{3}{|c|}{$\frac{\text { After bronchodilator }}{\text { PEFR }\left(/ \min ^{-1}\right) \S}$}} & \multirow{3}{*}{$\begin{array}{l}\text { Subjective } \\
\text { benefit }\end{array}$} \\
\hline & \multirow[t]{2}{*}{ Placebo } & \multirow[t]{2}{*}{ Active } & \multirow[t]{2}{*}{ Placebo } & \multirow[t]{2}{*}{ Active } & & & & & & & \\
\hline & & & & & Placebo & Active & $p_{+}^{+}$ & Placebo & Active & $p_{+}^{+}$ & \\
\hline 1 & 0.83 & 0.85 & 83 & 85 & $183 \pm 4$ & $218 \pm 4$ & $<0.001$ & & & & 0 \\
\hline 2 & $1 \cdot 23$ & $1 \cdot 46$ & 77 & 91 & $189 \pm 4$ & $230 \pm 3$ & $<0.001$ & $212 \pm 3$ & $242 \pm 4$ & $<0.001$ & + \\
\hline 3 & $2 \cdot 16$ & $2 \cdot 30$ & 90 & 96 & $296 \pm 6$ & $306 \pm 5$ & 0.009 & & & & + \\
\hline 4 & 1.49 & $1 \cdot 56$ & 74 & 78 & $191 \pm 6$ & $193 \pm 5$ & NS & $238 \pm 4$ & $247 \pm 4$ & 0.05 & ++ \\
\hline 6 & $2 \cdot 09$ & $2 \cdot 45$ & 80 & 94 & $177 \pm 5$ & $170 \pm 6$ & NS & & & & 0 \\
\hline 8 & $2 \cdot 58$ & $2 \cdot 78$ & 92 & 99 & $389 \pm 1$ & $390 \pm 2$ & NS & & & & 0 \\
\hline 9 & $2 \cdot 47$ & 3.06 & 69 & 85 & $349 \pm 6$ & $395 \pm 9$ & $<0.001$ & & & & ++ \\
\hline 10 & $1 \cdot 63$ & $1 \cdot 71$ & 86 & 90 & $214 \pm 8$ & $215 \pm 4$ & NS & $302 \pm 4$ & $289 \pm 5$ & 0.02 & 0 \\
\hline 11 & 0.71 & 0.89 & 71 & 89 & $192 \pm 3$ & $193 \pm 2$ & NS & $210 \pm 3$ & $211+2$ & NS & + \\
\hline 12 & 0.95 & $1 \cdot 18$ & 68 & 84 & $140 \pm 6$ & $140 \pm 7$ & $0.00 t$ & & & & 0 \\
\hline 13 & 1.04 & 1.04 & 77 & 77 & $149 \pm 3$ & $142 \pm 4$ & NS & & & & ++ \\
\hline 14 & $2 \cdot 46$ & $2 \cdot 59$ & 79 & 83 & $329 \pm 9$ & $340 \pm 6$ & NS & & & & 0 \\
\hline 15 & 1.06 & $1 \cdot 33$ & 73 & 92 & $155 \pm 3$ & $189 \pm 2$ & $<0.001$ & $186 \pm 3$ & $220 \pm 2$ & $<0.001$ & ++ \\
\hline 16 & $1 \cdot 16$ & $1 \cdot 25$ & 68 & 74 & $155 \pm 6$ & $137 \pm 3$ & 0.006 & $233 \pm 5$ & $219 \pm 3$ & 0.01 & ++ \\
\hline 19 & $1 \cdot 25$ & 1.49 & 74 & 88 & $140 \pm 6$ & $140 \pm 6$ & NS & & & & + \\
\hline 20 & $2 \cdot 21$ & $2 \cdot 68$ & 74 & 89 & $380 \pm 4$ & $400 \pm 4$ & 0.005 & & & & 0 \\
\hline 21 & $1 \cdot 15$ & $1 \cdot 43$ & 70 & 86 & $167 \pm 3$ & $200 \pm 5$ & $<0.001$ & $210 \pm 4$ & $244 \pm 4$ & $<0.001$ & ++ \\
\hline 22 & $2 \cdot, 6$ & $2 \cdot 15$ & 90 & 90 & $316 \pm 5$ & $324 \pm 4$ & NS & & & & 0 \\
\hline 23 & $1 \cdot 56$ & $1 \cdot 81$ & 74 & 86 & $306 \pm 4$ & $350 \pm 4$ & $<0.001$ & $352 \pm 3$ & $392 \pm 3$ & $<0.001$ & ++ \\
\hline Mean & $1 \cdot 59$ & $1 \cdot 79$ & 77 & 87 & $232 \pm 5$ & $247 \pm 4$ & $<0.001$ & $243 \pm 4$ & $258 \pm 3$ & $<0.001$ & \\
\hline
\end{tabular}

NS $=$ not significant $=p>0.05$.

${ }^{*} \mathrm{FEV}_{1}$ as a percentage of the best recorded value during the previous three years, including steroid trial periods.

$\uparrow$ Mean PEFR (average of morning and evening) \pm SEM before use of inhaled $\beta$-agonists.

tp value as determined from paired $t$ test.

$\S M$ ean PEFR (average of morning and evening) \pm SEM, 15 minutes after use of inhaled $\beta$-agonists.

$0=$ no benefit or detriment; $+=$ moderate improvement; $++=$ marked improvement.

four responders to aminophylline retained their responsiveness to $\beta$-agonists (table 2 ). The other patients, using inhaled $\beta$-agonists as required, reduced their daily usage slightly from a mean of 5.4 puffs while on the placebo to 4.2 puffs on the active drug $(\mathrm{p}=0 \cdot 1)$.

\section{UNWANTED EFFECTS}

Seven of the 19 patients complained of nausea, headache, or upper abdominal discomfort, as did all five of the patients unable to complete the trial satisfactorily. The severity and duration of these symptoms were variable (table 1). 


\section{Discussion}

We aimed to examine whether sustained release oral aminophylline was a useful addition to the treatment of some of the more poorly-controlled patients attending our asthma clinic. These patients were mainly in late middle age, so our findings do not necessarily reflect the responsiveness of younger patients to aminophylline. The potential for further reversibility of airflow obstruction in our patients was possibly fairly small as the mean weekly $\mathrm{FEV}_{1}$, while receiving the active preparation, for the whole group reached $87 \%$ of the best value recorded during the previous three years, which included periods on high-dose steroid therapy in several patients. This compares with the $77 \%$ achieved while on placebo (table 2 ).

Seven of the 19 patients failed to achieve either a statistically significant increase in daily PEFR or a mean increase of $200 \mathrm{ml}$ or more in their $\mathrm{FEV}_{1}$ while receiving the active preparation (table $2)$. Of these, three $(4,13$, and 16) were clearly unresponsive to the drug, since they achieved reasonable plasma levels of theophylline and were submaximally bronchodilated. Of the others, patient 10 was undoubtedly underdosed and patients 14 and 22 also might have benefited from larger loses. In addition patient 22 was already close to maximal bronchodilation. Patient 11 was one of two steroid unresponsive patients in the trial, and the mean increase in his $\mathrm{FEV}_{1}$ of $180 \mathrm{ml}$ represented a substantial part of his available reversibility.

We have data on the relation between the response to inhaled $\beta$-agonists (salbutamol) and to oral aminophylline in eight of the patients (table 2). Four responded to aminophylline and all retained their responsiveness to $\beta$-agonists, so that the effects appeared to be additive. We did not attempt to show whether this additional benefit could have been achieved by increasing the dose of salbutamol. The four patients who did not respond to aminophylline nevertheless showed a good response to $\beta$-agonists. Our results suggest that a combination of oral aminophylline and salbutamol may be useful, particularly if side-effects from a higher dose of either drug used alone are proving troublesome.

A wide dose range ( 8.6 to $30.8 \mathrm{mg} \mathrm{kg}^{-1} 24 \mathrm{hr}^{-1}$ ) was required to achieve similar plasma levels in the 23 patients who had no overt liver disease or cardiac failure (table 1). Variation did not appear to depend on age, which contrasts with data on intravenous aminophylline therapy. ${ }^{7}$ One patient with liver disease required a significantly reduced dose $\left(7.0 \mathrm{mg} \mathrm{kg}^{-1} 24 \mathrm{hr}^{-1}\right)$, which is in keeping with $\stackrel{\overrightarrow{\mathrm{O}}}{\stackrel{\vec{O}}{*}}$ experience using intravenous aminophylline. ${ }^{7} \frac{7}{0}$ Clearly, as our doses varied from $225 \mathrm{mg}$ up to $1125 \mathrm{mg}$ 12-hourly, the standard recommended $\frac{\bar{\sigma}}{\frac{\sigma}{a}}$ dosage of 225 or $450 \mathrm{mg}$ 12-hourly will result in a $\stackrel{\varnothing}{\unrhd}$ significant number of patients being underdosed. Measurement of plasma or serum theophylline levels by high pressure liquid chromatography ${ }^{6}$ is quick and accurate but unfortunately not as yet $\overrightarrow{\vec{\omega}}$ widely available. If such measurements are not $\stackrel{\omega}{\sigma}$ available the patient could be started on a low $\overrightarrow{\vec{x}}$ dose, which could be increased progressively to doses greater than $450 \mathrm{mg}$ 12-hourly on occasions. From our experience nausea, headache, or ab- $\omega$ dominal discomfort are likely to occur before $\omega$ the plasma theophylline level achieves dangerously high levels - that is, $25 \mathrm{mg} \mathrm{1}^{-1}{ }^{8}$ above which $\rightarrow$ convulsions and cardiac arrythmias may occur, $\frac{D}{0}$ but this may not invariably be the case. Only two of our 24 patients would have had subtherapeutic $\vec{\oplus}$ plasma theophylline levels below $10 \mathrm{mg}^{-1}$ on $\stackrel{\infty}{\rightarrow}$ dosage regimens of $16 \mathrm{mg} \mathrm{kg}^{-1} 24 \mathrm{hr}^{-1}$ and only three would have potentially been at risk of unacceptably high levels.

We were disappointed with the high incidence of nausea, headache, and abdominal discomfort $\frac{\otimes}{\circ}$ found in patients receiving the active preparation. $\stackrel{2}{\Rightarrow}$ Twelve of the original 24 patients complained of $\frac{0}{3}$ such side-effects and in six they were sufficiently severe to exclude maintenance therapy with the drug. The side-effects tended to be most severe four to six hours after taking a dose and thuso would coincide with the peak plasma levels. ${ }^{5}$ There was no relationship between the plasma theo- 0 phylline levels at which side-effects occurred in different patients but in any individual patiento the severity of the effects depended on the plasma theophylline concentration.

We conclude that sustained release oral amino-s phylline can produce modest but useful additionalo bronchodilatation in some patients whose airflown obstruction is inadequately controlled by other drugs. This may be particularly helpful if it is un desirable to increase the doses of existing medications such as oral steroids. Unfortunately, the high incidence of side-effects and the wide vario ation in optimum dosage for different patientso restrict the drug's usefulness. However, our find? ings suggest that if asthmatic symptoms are in $-\frac{0}{3}$ adequately controlled by inhaled $\beta$-agonists then it may be more logical to add oral theophylline? compounds rather than further (oral) $\beta$-agonis $\underline{B}$ therapy to their treatment. They also underline the need for estimating plasma theophylline levels in clinical trials of theophylline compounds. 
We thank Napp Laboratories for provision of the Phyllocontin and placebo tablets and for financial support.

\section{References}

1 Piafsky KM, Ogilvie RI. Dosage of theophyllines in bronchial asthma. $N$ Engl J Med 1975; 292: 1218-22.

2 Mitenko PA, Ogilvie RI. Rational intravenous doses of theophylline. $N$ Engl J Med 1973; 289: 600-3.

3 Turner-Warwick M. Study of theophylline plasma levels after oral administration of new theophylline compounds. $\mathrm{Br}$ Med J 1957; 3:67-9.

4 Jenne JW, Wyze E, Rood FS, MacDonald FM. Pharmacokinetics of theophylline. Application to adjustment of the clinical dose of aminophylline. Clin Pharmacol Therap 1972; 13:349-60.

5 Trembath PW, Boobis SW, Richens A. Theophylline: biochemical pharmacology and pharmacokinetics. J Int Med Res 1979; 7: suppl 1, 4-15.

6 McKenzie SA, Edmunds AT, Baillie E, Meek J. Clinical applications of serum theophylline measurement by high pressure liquid chromatography. Arch Dis Child 1978; 53:322-5.

7 Jusko WJ, Koup JR, Vance JW, Schentag JJ, Kuritzky P. Intravenous theophylline therapy: nomogram guidelines. Ann Intern Med 1977; 86:400-4.

8 Jacobs MH, Senior RM, Kessler G. Clinical experience with theophylline. Relationships between dosage, serum concentration and toxicity. JAMA 1976; 235:1983-6. 